\title{
复 \\ Tratamento de resíduos em abatedouros frigoríficos de bovinos em Pernambuco
}

\author{
[Treatment of residues from cattle slaughterhouses in Pernambuco]
}

\section{"Artigo Científico/Scientific Article"}

\author{
Elâne Rafaella Cordeiro Nunes Serafim", Maria de Fatima Silva², Eder Abner Cordeiro Nunes ${ }^{3}$, \\ Elvis Thiago Cordeiro Nunes ${ }^{4}$, Silvio Serafim de Oliveira ${ }^{5}$, Daniel Friguglietti Brandespim ${ }^{1,6}$
}

\begin{abstract}
${ }^{1}$ Programa de Pós-graduação em Ciência Animal Tropical, Universidade Federal Rural de Pernambuco, Recife-PE, Brasil. ${ }^{2}$ Programa de Pós-graduação em Administração e Desenvolvimento Rural, Universidade Federal Rural de Pernambuco, RecifePE, Brasil

${ }^{3}$ Setor de Vigilância Sanitária, Secretaria Municipal de Saúde, Santana do Ipanema-AL, Brasil.

${ }^{4}$ Setor de Vigilância em Saúde, Secretaria Municipal de Saúde, Maraial-PE, Brasil.

${ }^{5}$ Programa de Pós-graduação em Tecnologias Ambientais, Instituto Federal de Alagoas, Marechal Deodoro-AL, Brasil.

${ }^{6}$ Departamento de Medicina Veterinária, Universidade Federal Rural de Pernambuco, Recife-PE, Brasil.

*Autor para correspondência/Corresponding author: E-mail: elane.rafaella@ gmail.com
\end{abstract}

\section{Resumo}

Nos abatedouros frigoríficos há produção de resíduos sólidos e líquidos, que caso não sejam tratados antes de sua destinação final ao meio ambiente pode acarretar prejuízos sanitários e ambientais em uma região. Sendo assim, buscou-se no presente estudo identificar se os abatedouros frigoríficos públicos municipais do Agreste Pernambucano realizam o tratamento de efluentes. Os dados foram coletados em 20 laudos técnicos emitidos pela Agência de Defesa Agropecuária Estadual, disponíveis no sítio eletrônico do Ministério Público do Estado de Pernambuco. Verificou-se que $85 \%$ dos abatedouros analisados não realizam tratamento dos efluentes. Conclui-se que os abatedouros frigoríficos do agreste pernambucano precisam implantar e/ou adequar os sistemas de tratamento de efluentes, minimizando assim os riscos sanitários e ambientais da população.

Palavras-chave: saúde pública; impactos; abate de bovino.

\begin{abstract}
In cattle slaughterhouses there is production of solid and liquid waste. Failure to treat such waste before it is disposed of in the environment may result in damage to human health and the surrounding environment. Thus, the present study had the objective to identify if the municipal public cattle slaughterhouses in the Agreste region of Pernambuco treat the effluents. The data were collected in 20 technical reports from the State Agropecuarian Defense Agency, available on the website of the Public Ministry of the State of Pernambuco. It was found that $85 \%$ of the slaughterhouses analyzed do not treat the effluents. It is concluded that slaughterhouses in Pernambuco should implement and / or adapt effluent treatment systems, minimizing the risks to the health of the population and the environment.
\end{abstract}

Keywords: public health; impacts; slaughter of cattle.

\section{Introdução}

No decorrer dos anos, com a evolução do ciclo produtivo da sociedade capitalista houve a extração de elementos e insumos no meio ambiente para a produção de alimentos e bens de consumo. Nesse processo de extração os diferentes setores produtivos geram resíduos e emitem poluentes, acarretando poluição e esgotamento dos recursos naturais (Pierre e Araujo, 2017).

A disposição e o gerenciamento dos resíduos sólidos e líquidos nos setores produtivos podem resultar em impactos à saúde humana e ambiental, que vêm sendo discutidos ao longo dos anos, com maior ênfase após as Conferências das Nações Unidas sobre Meio Ambiente e Desenvolvimento, ECO-92 e a Rio+20 (Silva et al., 2017). Após esses eventos, as organizações governamentais e sociais 
intensificaram a busca por soluções para minimizar as alterações no sistema climático, discutindo estratégias para conciliar o desenvolvimento com a conservação e a proteção do ecossistema, assim como citado entre os 17 Objetivos do Desenvolvimento Sustentável (ODS) da Agenda 2030 (Buss, 2017).

Uma das estratégicas utilizadas no setor produtivo é a implantação de um Sistema de Gestão Ambiental (Seganfredo, 2007), para incluir valores do desenvolvimento sustentável na organização social e nas metas da empresa e da administração pública, de modo a controlar e assegurar $\mathrm{o}$ cumprimento da Lei ou normas que estão estabelecidas (Gazzinelli, 2001). Essa conscientização dos efeitos nocivos dos resíduos no meio ambiente associada à implantação de leis ambientais severas, tornou o gerenciamento ambiental uma questão fundamental para abatedouros frigoríficos (Pierre e Araujo, 2017).

Nesses estabelecimentos, os resíduos podem ser vísceras de animais abatidos, fragmentos cárneos, sangue, conteúdo intestinal, pelos, ossos, penas, gorduras e águas residuais. Do ponto de vista econômico e ambiental, muitos destes produtos residuais poderiam ser transformados em subprodutos, alimento de animais, indústria de rações ou fertilizantes (Pacheco, 2008), além do tratamento visando à reciclagem energética e preservação do meio ambiente (Costa et al., 2005).

Apesar da possibilidade da utilização, a destinação dos resíduos de abatedouros causa preocupação pelo gradativo aumento no volume da produção dos mesmos (Gazzinelli, 2001) e pelo alto valor de matéria orgânica que possuem, podendo carrear agentes etiológicos de doenças transmissíveis, ocasionando impactos no ambiente interno e externo de trabalho (Pardi et al., 2005). No caso de águas residuais podem causar danos às águas fluviais e ao solo. Os resíduos sólidos ocasionam sérios prejuízos ao ar, ao solo e à saúde, pois, frequentemente, são depositados em lixões, terrenos particulares ou queimados como combustíveis fósseis (Araújo e Costa, 2014).

De acordo com Araujo e Costa (2014) muitos abatedouros frigoríficos, públicos e/ou privados utilizam padrões insustentáveis de produção e consumo, não atendendo as normas postas na legislação ambiental, favorecendo a propagação de fatores de risco ao meio ambiente, a saúde da população e a economia regional.

Em relação a abatedouros com administração municipal, Foerster (2009) citou que os resíduos em matadouros pernambucanos são geralmente lançados próximos ao estabelecimento, nas superfícies do solo, riachos e rios, sem qualquer tipo de tratamento prévio, ou transportado para lixões ou a cremação, gerando custo, degradando o meio ambiente e favorecendo a disseminação de agentes causadores de doenças.

Apesar da importância do tema em questão, há uma escassez de pesquisas acerca deste tema em relação aos resíduos produzidos em abatedouros frigoríficos públicos municipais do Estado de Pernambuco. Neste sentido, o presente estudo teve como objetivo identificar se os abatedouros frigoríficos públicos municipais do Agreste Pernambucano realizam o tratamento de efluentes.

\section{Material e Métodos}

A pesquisa foi realizada por meio de dados secundários disponíveis no Ministério Público Estadual (MPPE), que remetem ao tratamento de efluentes de abatedouros frigoríficos do agreste pernambucano. Esta região é composta por 71 municípios que são caracterizados pela consolidada estrutura urbana, com razoável dinamismo no setor industrial e comercial (IBGE, 2014).

A abordagem do problema foi de caráter qualitativo, em que os fenômenos estudados foram interpretados e compreendidos, destacando-se as características encontradas para análise detalhada sobre os comportamentos (Marconi e Lakatos, 2010).

Quanto ao procedimento classifica-se como pesquisa bibliográfica que, segundo Martins (2000), explica e discuti um tema ou um problema com base nas referências teóricas publicadas em livros, revistas, periódicos etc.

Em relação aos objetivos delineados para o estudo, a pesquisa foi descritiva, pois teve como principal objetivo descrever características de determinada população, utilizando técnicas padronizadas de coleta de dados (Gil, 2008).

A coleta de dados foi realizada durante o mês de março do ano de 2017. Analisou-se 20 laudos de vistoria sanitária em abatedouros frigoríficos emitido pela Agencia de Defesa Agropecuária de Pernambuco, no período de 2008 a 2013, os quais estão disponíveis no sítio eletrônico do Ministério Público Estadual (MPPE). É importante citar que o acesso a essas informações é garantido e regulamentado pela Lei Federal $\mathrm{N}^{\circ} 12.527$, de 18 de novembro de 2011 e pelo Decreto $\mathrm{N}^{\circ} 7.724$, de 
16 de maio de 2012, os quais dispõem sobre o acesso as informações (Brasil, 2011; Brasil, 2012).

Após a coleta de dados, os mesmos foram tabulados em planilha eletrônica do Microsoft Excel, por município, tipo de tratamento de efluentes, destinação de resíduos, e ano inspeção. Em seguida foram analisados mediante análise estatística descritiva qualitativa.

\section{Resultados}

Foi observado que 20 laudos de vistoria sanitária em abatedouros frigoríficos emitido pela Agencia de Defesa Agropecuária de Pernambuco, no período de 2008 a 2013, de municípios do agreste, conforme a Tabela 1 .
Em relação ao tratamento de efluentes, verificou-se que em 20\% (4/20) dos estabelecimentos houve registro de tratamento, sendo o principal destino a Lagoa de decantação. Em 15\% (03/20) foi registrado o uso de esterqueira, crivo e/ou fossa séptica. E em um citava a rede de esgoto como destino dos resíduos, porém não há registro sobre o tratamento realizado antes da destinação.

Observou-se ainda, de acordo com os dados da Tabela 1, que $80 \%$ (16/20) dos abatedouros frigoríficos vistoriados não realizavam tratamento de efluentes, e os resíduos eram destinados ao meio ambiente, no terreno do próprio estabelecimento e áreas próximas.

Tabela 1. Relação dos abatedouros frigoríficos analisados, em relação a tratamento e destinação de efluentes e ano de inspeção realizado pela Agência de Defesa e Fiscalização Agropecuária de Pernambuco.

\begin{tabular}{|c|c|c|c|}
\hline Município & $\begin{array}{l}\text { Tratamento } \\
\text { de efluentes }\end{array}$ & Destinação de resíduos & Ano inspeção \\
\hline Bom Conselho & Sim & Rede de esgoto & 2013 \\
\hline Brejão & Não há & Meio ambiente & 2012 \\
\hline Cachoeirinha & Não há & Meio ambiente & 2011 \\
\hline Caetés & Não há & Meio ambiente & 2011 \\
\hline Calçado & Sim & Lagoa de decantação & 2012 \\
\hline Canhotinho & Não há & Meio ambiente & 2008 \\
\hline Caruaru & Não há & Meio ambiente & 2010 \\
\hline Gravata & Não há & Meio ambiente & 2010 \\
\hline Iati & Sim & $\begin{array}{l}\text { Esterqueira; Crivo; Fossa séptica; } \\
\text { Lagoa de decantação }\end{array}$ & 2012 \\
\hline Jatauba & Não há & Meio ambiente & 2013 \\
\hline Jucati & Não há & Meio ambiente & 2011 \\
\hline Jupi & Não há & Meio ambiente & 2012 \\
\hline Palmerina & Não há & Meio ambiente & 2013 \\
\hline Paranatama & Não há & Meio ambiente & 2011 \\
\hline Pedra & Não há & Meio ambiente & 2012 \\
\hline Sairé & Não há & Meio ambiente & 2013 \\
\hline Saloa & Não há & Meio ambiente & 2010 \\
\hline Santa Cruz do Capibaribe & Não há & Meio ambiente & 2013 \\
\hline São Caetano & Sim & $\begin{array}{l}\text { Esterqueira; Crivo; Caixa de gordura; } \\
\text { Fossa séptica; Lagoa de decantação }\end{array}$ & 2013 \\
\hline São João & Não há & Meio ambiente & 2012 \\
\hline Teresinha & Não há & Meio ambiente & 2012 \\
\hline
\end{tabular}

Fonte: MPPE - Ministério Público de Pernambuco. Matadouros: laudos e pareceres técnicos, 2017.

\section{Discussão}

Apesar de apenas 20\% dos abatedouros frigoríficos da região do agreste pernambucano realizarem o tratamento de efluente é de extrema importância para a avaliação do impacto ambiental que tais informações representam. Sabe-se que na atividade de abate de bovinos há um descarte expressivo em volume de efluente líquido, que contêm sangue, gordura, excrementos, substâncias contidas no trato digestivo dos animais, fragmentos de tecidos, entre outros, caracterizando um efluente com elevada concentração de matéria orgânica (Santos et al., 2011). Esses efluentes só poderão ser lançados diretamente nos corpos receptores após o devido tratamento (Brasil, 2011).

A ausência do tratamento de efluentes em $80 \%$ dos abatedouros frigoríficos do agreste pernambucano tem grande relevância do ponto de vista de saúde pública e social, principalmente ao reconhecer que as águas residuais provenientes da 
higienização de pisos, equipamentos, carcaças, e da higienização de currais, corredores, caminhões e animais são os fatores que representam os maiores riscos e impactos ambientais gerados pela indústria de abate animal (Rabelo et al., 2014).

A contaminação ambiental com resíduos constitui um grave problema de saúde pública, principalmente em classe menos favorecida, devido às condições de vulnerabilidade caracterizadas pela falta de saneamento básico e ineficiência de sistemas preventivos de saúde e de segurança alimentar intensificando o agravamento das condições de vida (Silva et al., 2012). Além disso, alguns dos resíduos desses estabelecimentos como o sangue, representam um grande potencial poluidor sobre os efluentes naturais, pois o sangue resultante do abate, quando não tratado ou utilizado para produção de farinha, é um agente de impacto sobre o ecossistema hídrico, pois eleva os níveis da demanda química de oxigênio a níveis altíssimos, por se tratar de um excelente meio de cultura para microrganismos (Rabelo, Silva e Peres, 2014).

A destinação incorreta de águas residuais pode até acarretar um ciclo de recontaminação da carcaça na própria sala de matança. Já houve detecção de bactérias do gênero Aeromonas e Escherichia coli $\mathrm{O} 26$ em água dos currais e água residuais da lavagem de carcaças (Rossi et al., 2000; Nespolo et al., 2014). A presença desses contaminantes biológicos merece atenção, pelo risco de expansão e distribuição de patógenos que acometem a população. Há relatos que os problemas originados nesse estabelecimento estendem-se pelo entorno do mesmo e alcançam áreas bastante distantes. Os dejetos e a água de lavagens misturam-se com sangue e fezes e são lançadas diretamente em um curso de água ou uma lagoa, normalmente assoreada e tomada pela vegetação. $\mathrm{E}$ quando há contaminação por coliformes do curso de água, como Escherichia coli, em valores acima do limite permitido, o mesmo não pode ser liberado para consumo humano, dessedentação animal ou para banho, chegando a haver restrições no uso da água para as atividades da agricultura (Silva et al., 2012).

Além dos danos aos cursos de água, esses efluentes gerados em abatedouros frigoríficos podem prejudicar o solo (Araújo e Costa, 2014), principalmente se o manejo, armazenamento e a disposição do mesmo ocorrerem de forma inadequada, tanto dos resíduos principais da produção quanto de resíduos secundários, que podem contaminar o solo e as águas superficiais e subterrâneas, tornando-os impróprios para qualquer uso e gerando danos a saúde pública (Pacheco, 2006)

A realidade encontrada em Pernambuco não difere de algumas regiões. No Estado do Sergipe, por exemplo, dos 59 abatedouros frigoríficos municipais 20 foram interditados pela Administração Estadual do Meio Ambiente do Estado de Sergipe e/ou Ministério Público Estadual ou desativados por irregularidades relacionadas à inadequação higiênica, despejos de efluentes, descarte inadequado de resíduos sólidos, carência de manutenção das lagoas de tratamento, e ausência dos parâmetros regidos pela legislação ambiental e sanitária vigente (Silva et al., 2012). No Estado do Maranhão, os impactos ambientais do abate de bovinos na cidade de São Luís também se relacionam com o armazenamento e transporte incorreto dos resíduos sólidos (Santos et al., 2014).

Em busca de adequar os matadouros municipais no padrão legal, alguns estados da região nordeste do país, como Pernambuco, Bahia e Sergipe implantaram programa de regionalização de abatedouros frigoríficos, com o intuito de substituir as pequenas e inadequadas unidades de abate dos municípios por abatedouros frigoríficos regionais, contemplando o abate sob as condições mínimas de higiene exigidas, o transporte das carcaças e vísceras para as sedes dos municípios inclusos em veículos refrigerados (Evangelista et al., 2011).

É importante citar que a interdição de abatedouros frigoríficos que não atendam os padrões legais são medidas necessárias para o bem da saúde pública e ambiental ao afastar o risco da população ser acometida por algum patógeno, entretanto há como consequência o desemprego nos municípios onde houve interdição e aumento no custo do produto para população de municípios que ficam mais afastados de abatedouros regionais. Além da possibilidade do aumento de abate clandestino nesses locais.

Essa situação evidência que ainda há aspectos sanitários e sociais que devem ser redimensionando na política de regionalização de abatedouros frigoríficos. Principalmente ao relacionar que a saúde é dever do Estado e direito de todos, garantido mediante políticas sociais e econômicas que visem à redução do risco de doenças e de outros agravos e ao acesso universal e igualitário às ações e serviços para sua promoção, proteção e recuperação (Brasil, 1998); e que é de 
competência do município o cuidado com a saúde e assistência pública (Brasil, 1990); e que todos têm direito ao meio ambiente ecologicamente equilibrado, e que o mesmo é bem de uso comum do povo e essencial à sadia qualidade de vida, impõe-se ao Poder Público e à coletividade o dever de defendê-lo e preservá-lo para as gerações presentes e futuras (Brasil, 1986).

Diante desse contexto, reforça-se a importância de adequação dos abatedouros frigoríficos ao correto manejo ambiental dos seus resíduos e implantação de alternativas de produção sustentável, adequando o processo industrial às condições e legislações ambientais, preservando-se assim a saúde pública e ambiental da região onde estejam inseridos (Santos et al., 2014).

\section{Conclusão}

Os abatedouros frigoríficos do agreste pernambucano precisam implantar e/ou adequar os sistemas de tratamento de efluentes, minimizando assim os riscos sanitários e ambientais, contribuindo significativamente para qualidade de vida da população, para redução da disseminação de patógenos e contaminação ambiental, e no cumprimento dos Objetivos do Desenvolvimento Sustentável (ODS) planejados para a Agenda do Desenvolvimento 2030. A efetivação dessa situação requer o redimensionamento de algumas políticas públicas e do fortalecimento estrutural e de recursos humanos dos órgãos fiscalizadores, e consequentemente a população será beneficiada com melhoria na segurança alimentar e na preservação do meio ambiente.

\section{Conflito de interesses}

Os autores declaram não existir conflito de interesse.

\section{Comitê de Ética}

Ressalta-se que as informações obtidas são regulamentadas pela legislação federal que permite o usuário a ter o acesso às informações públicas (Lei Federal $\mathrm{N}^{\mathrm{o}} 12.527$, de 18 de novembro de 2011, Decreto No 7.724, de 16 de maio de 2012).

\section{Referências}

Araújo, P.P.P.; Costa, L.P. Impactos ambientais nas atividades de abate de bovinos: um estudo no matadouro público municipal de CaicóRN. Revista Halos, 1:1-20, 2014.

BRASIL. Conselho Nacional do Meio Ambiente. Resolução n. 01, de 23 de janeiro de 1986.
Dispõe sobre critérios básicos e diretrizes gerais para a avaliação de impacto ambiental. Diário Oficial [da] República Federativa do Brasil, Poder Executivo, Brasília, DF, 17 fev. $1986 . \quad$ Disponível em: <http://www.mma.gov.br/port/conama/res/re s86/res0186.html >. Acesso em: 06 jun. 2017.

BRASIL. Constituição da República Federativa do Brasil de 1988. Diário Oficial [da] República Federativa do Brasil, Poder Executivo, Brasília, DF, 5 out 1988.Disponível em: < http://www.planalto.gov.br/ccivil_03/constitu icao/constituicao.htm>. Acesso em: 06 jun. 2017.

BRASIL. Lei $\mathrm{n}^{\mathbf{0}} \mathbf{8 . 0 8 0}$, de 19 de setembro de 1990. Dispõe sobre as condições para a promoção, proteção e recuperação da saúde, a organização e o funcionamento dos serviços correspondentes e dá outras providências. Diário Oficial [da] República Federativa do Brasil, Poder Executivo, Brasília, DF, 20 set. 1990. Disponível em: < http://www.planalt o.gov.br/ccivil_03/leis/18080.htm>. Acesso em: 06 jun. 2017.

BRASIL. Conselho Nacional do Meio Ambiente. Resolução $n^{\circ}$ 430, de 13 de maio de 2011. Dispõe sobre as condições e padrões de lançamento de efluentes, complementa e altera a Resolução no 357, de 17 de março de 2005. Diário Oficial [da] República Federativa do Brasil, Poder Executivo, Brasília, DF, 16 mai. 2011. Disponível em: < http://www.mma.gov.br/port/conama/legiabr e.cfm?codlegi=646>. Acesso em: 03 jun. 2017.

BRASIL. Lei $\mathbf{n}^{0} \mathbf{1 2 . 5 2 7}$, de 18 de novembro de 2011. Regula o acesso a informação. Diário Oficial [da] República Federativa do Brasil, Poder Executivo, Brasília, DF, 18 nov. 2011. Disponível em: <http://www.planalto.gov.br/ccivil_03/_ato2 011-2014/2011/lei/112527.htm>. Acesso em: 03 jun. 2017.

BRASIL. Decreto $\mathbf{n}^{\mathbf{7}} \mathbf{7 . 7 2 4}$, de 16 de maio de 2012. Regulamenta a Lei no 12.527 , de 18 de novembro de 2011, que dispõe sobre o acesso a informações. Diário Oficial [da] República Federativa do Brasil, Poder Executivo, Brasília, DF, 18 abr. 2012. Disponível em: <http://www.planalto.gov.br/ccivil_03/_ato2 011-2014/2012/decreto/d7724.htm>. Acesso em: 03 jun. 2017. 
Buss, P. Agenda 2030: Onde estamos hoje? Radis: comunicação e saúde, 177: 22-26, 2017.

Costa, M.S.D. M.; Costa, L.A.D.M.; Sestak, M.; Olibone, D.; Sestak, D.; Kaufmann, A.V.. Rotta, S.R. Compostagem de resíduos da indústria de desfibrilação de algodão. Engenharia Agrícola, 2(25):540-548, 2005.

Demajorovic, J. "A evolução dos modelos de gestão de resíduos sólidos. Seus instrumentos." Cadernos Fundap, 20:47-58, 1996.

Evangelista, F.R.; Oliveira, A.A.; Santos, J.A.N.; Nogueira-Filho, A.; Coelho, J.D. Caracterização do sistema de abate de bovinos no Nordeste. Informe rural ETENE, 8(5), 2011.

Foerster, P.J.E. A situação dos matadouros municipais. Recife: CONSEMA, 2009.

Gaio, R.; Carvalho, R.B.; Simões, R. Métodos e técnicas de pesquisa: a metodologia em questão. In: Gaio, R. (org.). Metodologia de pesquisa e produção de conhecimento. Petrópolis: Vozes, 2008.

Gazzinelli, M.F.; Lopes, A.; Pereira, W.; Gazzinelli, A. Educação e participação dos atores sociais no desenvolvimento de modelo de gestão do lixo em zona rural em Minas Gerais. Educação Social, 22(74):225-241, 2001.

Gil, A.C. Como elaborar projetos de pesquisa. 7. ed. São Paulo: Atlas, 2008.192 p. IBGE. Nota técnica estimativas da população dos municípios brasileiros com data de referência em $1^{\text {o }}$ de julho de 2014 . Disponível em: <http://www.ibge.gov.br/ home/presidencia/noticias/pdf/analise_estimati vas_2014.pdf> Acesso em: 17 mar. 2017.

Marconi, M.A. Lakatos, E.M. Metodologia científica. 7.ed. São Paulo: Atlas, 2010.

MPPE - Ministério Público de Pernambuco. Matadouros: laudos e pareceres técnicos. Disponível em: $<$ http://www.mppe.mp.br/siteantigo/siteantigo. mppe.mp.br/index.pl/caop_cons_matadouros_1 audose $1 \mathrm{~b} 4$.html? func $=$ view\& wid $=$ bhgatKNGjx eqHeiaFv52gg\&pn=2>. Acesso: 13 mar 2017.

Nespolo, N.M.; Saba, R.Z.; Rossatelli, D.A.; Fairbrother, J.M.; Rossi Júnior, O.D. Ocorrência de Escherichia coli O157:H7 e O26 sorbitol negativas em matadouro frigorífico de bovino e suscetibilidade a antimicrobianos. Arquivos do Instituto

Biológico, 3(81): 209-217, 2014.

Pacheco, J.W. Guia técnico ambiental de abates (bovino e suíno) In: Pacheco, J.W.; Yamanaka, H.T. São Paulo: CETESB, p.98, 2006.

Pacheco, J.W. Guia técnico ambiental de frigoríficos - industrialização de carnes (bovina e suína). São Paulo: CETESB (Série P + L), 2008.

Pardi, C.M. Constituintes básicos da carne. In: Pardi C. M.; Antos F.I., Souza, R.E.; Pardi, S.H. Ciência, higiene e tecnologia da carne. 2. ed. Goiânia: Ed. UFG, 2005. v.1, p. 52-70.

Pierre, F.C.; Araujo, S.M.F. Tratamento de resíduos em frigorífico de bovino corte. Tekhne e Logos, 8(4):81-93, 2017.

Rabelo, M.H.S.; Silva, E.K.; Peres, A.P. Análise de Modos e Efeitos de Falha na avaliação dos impactos ambientais provenientes do abate animal. Engenharia Sanitária Ambiental, 1(19): 79-86, 2014.

Rossi, J.R.O.D.; Amaral, L.A.; Nader-Filho, A. Bactérias do gênero Aeromonas em água de matadouro bovino. Arquivo Brasileiro de Medicina Veterinária e Zootecnia, 5(52): 549-553. 2000.

Santos, C.A.S.; Torres, C.J.F.; Silva N.L; Silva, J.O.; Rocha, F.A. Sistema de tratamento de efluentes de matadouro bovino utilizando lagoas de estabilização. Enciclopédia Biosfera, Centro Científico Conhecer, 13(7):195-1297, 2011.

Santos, J.J.N.; Sousa, I.C.S.; Bezerra, D.C.C.; Silva, V.C. Chaves, N.P. Desafios de adequação à questão ambiental em frigoríficos na cidade de São Luís, Maranhão: diagnóstico de situação. Arquivos do Instituto Biológico, 4(81):315-321, 2014.

Seganfredo, M.A.; Gestão ambiental na suinocultura. Brasília-DF, EMBRAPA Suínos e Aves/EMBRAPA, p. 302, 2007.

Silva, E.L.; Silva, M.F.; Nunes, E.R.C.; Silva, J.M.; Oliveira, S.S. O Desenvolvimento Sustentável na Economia brasileira. Empreendedorismo, Gestão e Negócio, 6(6):55-72, 2017.

Silva, G.N.; Madi, R.R.; Melo, C.M.; Fonseca, V. Matadouros públicos e saúde ambiental em Sergipe. Saúde e Sociedade, 4 (21):10131021, 2012. 